\title{
Methylcarbonate and Bicarbonate Phosphonium Salts as Catalysts for the Nitroaldol (Henry) Reaction
}

\author{
Massimo Fabris, ${ }^{\dagger}$ Marco Noè, ${ }^{\dagger}$ Alvise Perosa, ${ }^{\dagger}$ Maurizio Selva, ${ }^{\dagger} * *$ and Roberto Ballini ${ }^{\ddagger}$ \\ ${ }^{\dagger}$ Dipartimento di Scienze Molecolari e Nanosistemi dell’Università Ca’ Foscari Venezia, calle Larga S. Marta, 2137-30123 Venezia, \\ Italy \\ ${ }^{\ddagger}$ School of Science and Technology, Chemistry Division, University of Camerino, Via S. Agostino 1, 62032 Camerino, Italy
}

Supporting Information

ABSTRACT: Phosphonium ionic liquids exchanged with bicarbonate and methylcarbonate anions (CILs) exhibit catalytic performances comparable to those of sterically hindered (non nucleophilic) organosuperbases such as DBU. At $25-50{ }^{\circ} \mathrm{C}$, under solventless conditions, CILs efficiently catalyze the Henry addition of different aldehydes and ketones to nitroalkanes: not only they allow the selective formation of nitroaldols but they unlock a novel high-yielding access to dinitromethyl derivatives of ketones.

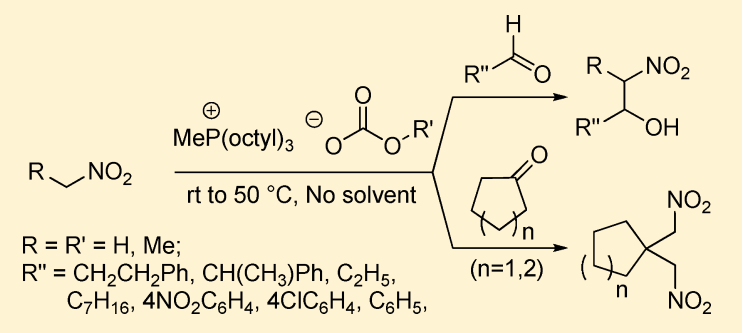

\section{INTRODUCTION}

Catalysis by ionic liquids (ILs) is gaining a preeminent position. ${ }^{1}$ Modern literature reports a number of transformations including esterifications, nitrations, aldol condensations, Friedel-Crafts substitutions, acetalysations, etc., where ILs as such or binary/ternary IL-based systems act as efficient catalysts. $^{2}$ A peculiar field is represented by $\mathrm{C}-\mathrm{C}$ bond-forming reactions, ${ }^{3}$ where catalysis by ILs is effective on both the kinetic and the chemoselectivity of such processes. Among several examples, a remarkable one is the Henry reaction of nitroalkanes with carbonyl derivatives. ${ }^{4}$ Different ILs of either acid or basic character including chloroaluminate systems, tetramethylguanidinium and quinolinium salts, (supported) basic 1,2-dimethylimidazolium hydroxides and acetates, as well as commercially available phosphonium-based ILs are reported as catalysts for such a process (Scheme 1$){ }^{5}$

Scheme 1

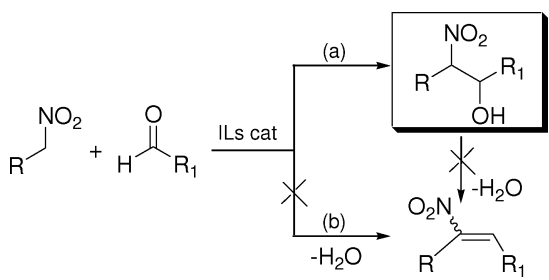

The mechanisms of activation of both nitroalkanes and aldehydes depend on the nature of the organocatalysts, nonetheless both acidic and basic ILs steer the Henry addition selectively to the formation of nitroaldols (Scheme1, top), while the competitive dehydration to conjugated nitroalkenes (Scheme1, bottom) is not observed.

As a part of our current research program on green methods for $\mathrm{C}-\mathrm{C}$ bond-forming reactions, ${ }^{6}$ we were interested to test the catalytic behavior of new ionic liquids recently synthesized by us, ${ }^{7}$ namely methyl carbonate and bicarbonate phosphonium salts (CILs, Scheme 2: 1a and $\mathbf{1 b}$ ).

Scheme 2

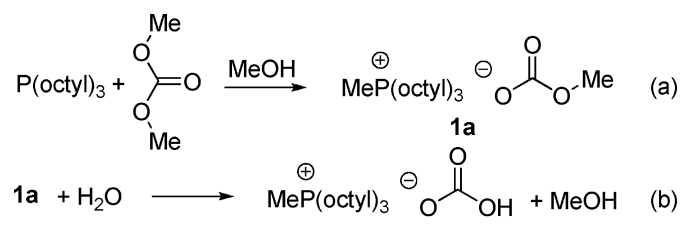

$1 \mathrm{~b}$

These compounds possess peculiarities which make them attractive in the context of this work: (i) they are unexpectedly strong base catalysts, as indicated by their performance in model Michael additions; ${ }^{7}$ (ii) they are halide-free and stable for months on the shelf; (iii) they are prepared through a simple green method based on the methylation of an alkyl phosphine with nontoxic dimethyl carbonate (DMC/MeO$\left.\mathrm{CO}_{2} \mathrm{Me}\right),{ }^{8}$ followed by a hydrolysis reaction in the case of $\mathbf{1} \mathbf{b}$; (iv) they can be used straight out from the reaction vessel since they are obtained in a high purity with no byproduct. In addition, a promoting effect by the phosphonium cation was foreseen, as hypothesized previously. ${ }^{5 \mathrm{f}}$

This paper reports an unprecedented application of methylcarbonate and bicarbonate salts $\mathbf{1 a}$ and $\mathbf{1 b}$. Both CILs, particularly $\mathbf{1 b}$, exhibit an excellent activity as catalysts for the Henry reaction. The condensation of aldehydes with nitroalkanes takes place under very mild solventless conditions: for example, at $25{ }^{\circ} \mathrm{C}$, the addition of nitroethane to 3phenylpropionaldehyde catalyzed by $\mathbf{1 a}$ or $\mathbf{1 b}$ is complete in

Received: November 18, 2011

Published: January 17, 2012 
80-100 min, at rates comparable to those achieved with powerful organic bases such as DBU. Although more demanding conditions $\left(50{ }^{\circ} \mathrm{C}, 20 \mathrm{~h}\right)$ are required for ketones, the use of CILs catalysts provides a novel approach for the double addition of nitromethane to rather hindered carbonyls of cyclohexanone and cyclopentanone.

\section{RESULTS AND DISCUSSION}

Different Catalysts. Onium salts $\mathbf{1 a}$ and $\mathbf{1 b}$ and four conventional bases including 1,8-diazabicyclo[5.4.0] undec-7ene (DBU), phenyltetramethylguanidine (PhTMG), triethylamine, and dimethylaminopyridine (DMAP) were used. The rationale for the choice of these bases was to operate under homogeneous conditions (as with ILs) and to cover a relatively wide $\mathrm{pK}$ range, approximately from 24 to 18 . $\mathrm{DBU}, \mathrm{Et}_{3} \mathrm{~N}$, and DMAP were commercially available, while PhTMG was prepared from 1,1,3,3-tetramethylurea and aniline, using a reported procedure. ${ }^{9}$

The addition of nitroethane to 3-phenylpropionaldehyde (PPA, 2a) was chosen as a model reaction (Scheme 3). ${ }^{10}$

\section{Scheme 3}

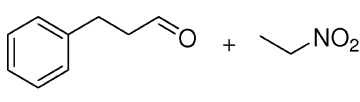

2a

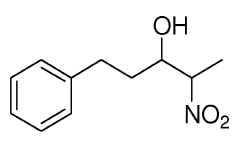

3a
Initial experiments were carried out in an NMR tube charged with PPA (67 mg, $0.50 \mathrm{mmol}$ ) and $\mathrm{CDCl}_{3}(1 \mathrm{~mL})$. This mixture was set to react with a solution $(0.18 \mathrm{~mL})$ of the selected base catalyst (see above: $0.025 \mathrm{mmol}, 0.05$ molar equiv with respect to PPA) in nitroethane $(188 \mathrm{mg}, 2.5 \mathrm{mmol}$, molar ratio nitroethane $/ \mathrm{PPA}=5$ ). Once the tube was inserted in the NMR spectrometer, spectra of the reacting mixture were recorded at defined time intervals for a total time of $190 \mathrm{~min}$.

This analysis showed that at $25{ }^{\circ} \mathrm{C}$, the Henry condensation proceeded smoothly and PPA produced the corresponding aldol derivative (3a) with total selectivity. In all experiments, both nitroaldol diastereoisomers were observed and the corresponding syn to anti ratio ranged from 50:50 to 69:31.

The integration of distinctive diagnostic signals of $\mathbf{2 a}$ and $3 \mathbf{a}$ allowed to collect kinetic profiles of the reactions automatically. Figure 1 illustrates the reaction PPA and nitroethane catalyzed by salt $\mathbf{1 b}$. Profiles are shown until $88 \mathrm{~min}$; after that time, the composition of the reaction mixture did not vary appreciably.

No appreciable interferences by the catalyst were observed, due to its very low concentration.

The comparison among different base catalysts are summarized in Figure 2 where the amount of nitroaldol 3a (sum of two diastereoisomers) is plotted against time.

The behavior of the different catalysts emerged quite clearly from these results. CILs, especially the bicarbonate salt $\mathbf{1 b}$, allowed a reaction outcome comparable to that obtained with DBU: after $25 \mathrm{~min}$, the conversion of PPA into aldol 3a was 80, 89 , and $94 \%$ in the presence of $\mathbf{1 a}, \mathbf{1} \mathbf{b}$, and DBU, respectively (blue, red, and black profiles). By contrast, the reaction turned out to be extremely sluggish using both PhTMG and $\mathrm{Et}_{3} \mathrm{~N}$. The corresponding conversions were 27 and $6 \%$, respectively, after $180 \mathrm{~min}$ (teal and fuchsia profiles). Finally, even after $20 \mathrm{~h}$, no appreciable formation of nitroaldol 3a was observed in the presence of DMAP (olive profile). The overall trend suggested a very good parallel between the catalytic activity and the

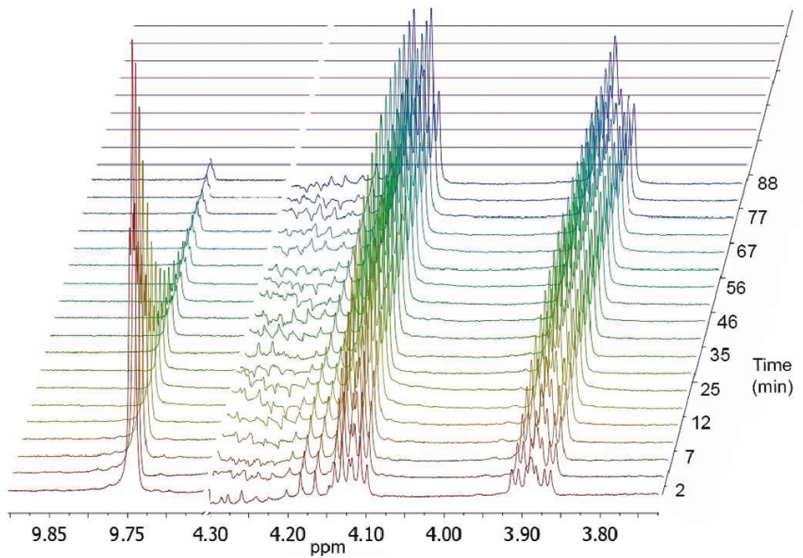

Figure 1. Henry condensation of 3-phenylpropionaldehyde with nitroethane carried out at $25^{\circ} \mathrm{C}$ in the presence of $\mathbf{1 b}$ as catalyst and $\mathrm{CDCl}_{3}$ as solvent. ${ }^{1} \mathrm{H}$ NMR spectra highlight signals of the aldehydic proton and of two nitroaldol diastereoisomers.

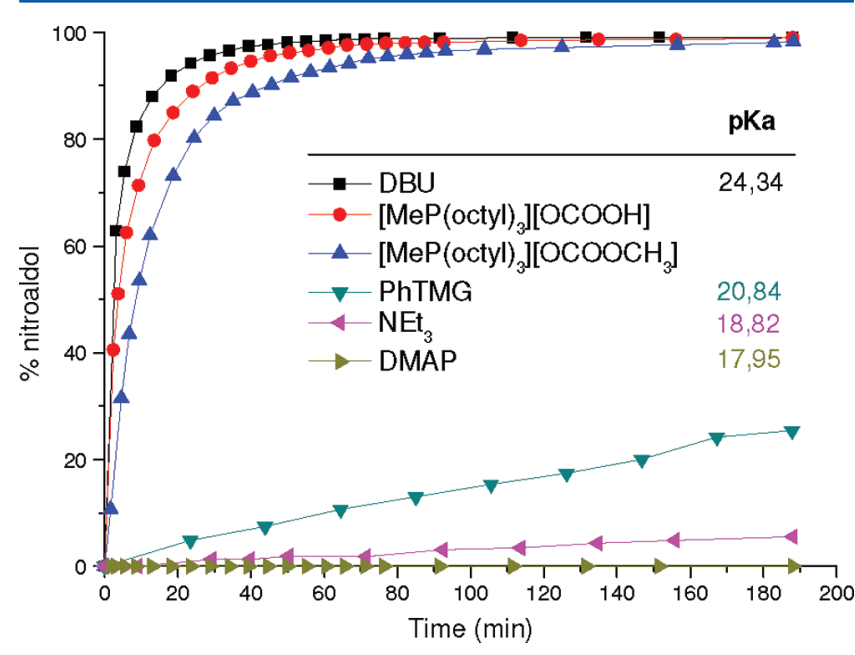

Figure 2. Comparison of different base catalysts (1a, 1b, DBU, PhTMG, $\mathrm{ET}_{3} \mathrm{~N}$, and DMAP) in the Henry condensation of 3phenylpropionaldehyde with nitroethane carried out at $25{ }^{\circ} \mathrm{C}$, in the presence of $\mathrm{CDCl}_{3}$ as solvent.

dissociation constants $\left(\mathrm{p} K_{\mathrm{a}}\right)$ of catalysts. The higher the $\mathrm{p} K_{\mathrm{a}}$ (24.34, 20.84, 18.82, 17.95 for DBU, PhTMG, $\mathrm{Et}_{3} \mathrm{~N}$ and DMAP, respectively, in acetonitrile solvent ${ }^{11}$ ), the stronger the base, the better its performance. In particular, the activity of compounds $\mathbf{1 a}$ and $\mathbf{1 b}$ placed them in the range of organosuperbases $\left(\mathrm{p} K_{\mathrm{a}} \sim 24\right)$ which appeared remarkable considering that both salts were exchanged with very poorly basic anions such as methylcarbonate and carbonate ones. Several factors, including solvation, ion pair strength, cation size, etc., offered an intriguing basis for discussion. At this stage, however, this was beyond the scope of the paper.

Henry Reaction of Different Aldehydes with Nitroethane. Salts $\mathbf{1 a}$ and $\mathbf{1 b}$ were further investigated as catalysts for the Henry condensation of different aldehydes with nitroethane. Optimization of the reaction of nitroethane with PPA and 4-nitrobenzaldehyde allowed to intensify the reaction conditions. With respect to Figure 1: (i) the CIL-to-aldehyde molar ratio was decreased to $0.01,{ }^{12}$ (ii) nitroethane was used in only 1.2 molar excess over aldehydes; (iii) no additional solvents were used. Five aliphatic and three aromatic aldehydes were considered (2a, $\mathrm{PhCH}_{2} \mathrm{CH}_{2} \mathrm{CHO} ; \mathbf{2 b}, \mathrm{PhCH}\left(\mathrm{CH}_{3}\right) \mathrm{CHO}$; 
2c, $\mathrm{C}_{2} \mathrm{H}_{5} \mathrm{CHO} ; 2$ d, $n$ - $\mathrm{C}_{10} \mathrm{H}_{21} \mathrm{CHO} ; 2 \mathrm{e},\left(\mathrm{CH}_{3}\right)_{3} \mathrm{CHO} ; 2$ f, 4 $\mathrm{NO}_{2} \mathrm{C}_{6} \mathrm{H}_{4} \mathrm{CHO} ; 2 \mathrm{~g}, 4-\mathrm{ClC}_{6} \mathrm{H}_{4} \mathrm{CHO} ; 2 \mathbf{2 h}, \mathrm{C}_{6} \mathrm{H}_{5} \mathrm{CHO}$; Scheme

Scheme 4

$$
\begin{aligned}
& \underset{\text { 2a-h }}{\stackrel{\mathrm{R}}{\mathrm{H}}}+\mathrm{NO}_{2} \frac{1 \text { a-b }}{\text { rt, No solvent }} \underset{\text { Ra-h }}{\mathrm{C}_{\mathrm{OH}}^{\mathrm{NO}_{2}}} \\
& \mathrm{R}=\mathrm{CH}_{2} \mathrm{CH}_{2} \mathrm{Ph}, \mathrm{CH}\left(\mathrm{CH}_{3}\right) \mathrm{Ph}, \mathrm{C}_{2} \mathrm{H}_{5}, \mathrm{C}_{7} \mathrm{H}_{16},\left(\mathrm{CH}_{3}\right)_{3} \mathrm{C} \\
& 4 \mathrm{NO}_{2} \mathrm{C}_{6} \mathrm{H}_{4}, 4 \mathrm{ClC}_{6} \mathrm{H}_{4}, \mathrm{C}_{6} \mathrm{H}_{5} \text {, }
\end{aligned}
$$

4). Accordingly, experiments were carried out at $25^{\circ} \mathrm{C}$, starting from $1.5 \mathrm{mmol}$ of aldehyde (87-255 mg), $1.8 \mathrm{mmol}$ of nitroethane $(135 \mathrm{mg})$, and $0.015 \mathrm{mmol}$ of $\mathbf{1 a}$ and $\mathbf{1 b}(7.4$ and $6.7 \mathrm{mg}$, respectively). Final reaction mixtures were quenched by adding a $1 \% \mathrm{HCl}$ aqueous solution $(1.0 \mathrm{~mL}$ ) (further details are in the Experimental Section). All reactions were highly selective toward the formation of nitroaldols: neither nitroolefins (Scheme 1) nor self-condensation products of enolizable aldehydes or other byproduct were observed by NMR. The nitroaldol derivatives were obtained as a mixture of diastereoisomers and purified by filtration over silica gel (2.0 g). Table 1 shows the amount (\%) of nitrolaldol products as

\begin{tabular}{|c|c|c|c|c|c|}
\hline \multirow[b]{2}{*}{ no. } & \multirow[b]{2}{*}{$\mathrm{RC}(\mathrm{O}) \mathrm{H}, \mathrm{R}$} & \multirow[b]{2}{*}{ time $(\mathrm{h})$} & \multicolumn{2}{|c|}{ nitroaldol product, 3} & \multirow[b]{2}{*}{ syn/anti ${ }^{c}$} \\
\hline & & & $\overline{(\%, \text { by NMR) }}$ & yield $^{b}(\%)$ & \\
\hline 1 & 2a: $\mathrm{CH}_{2} \mathrm{CH}_{2} \mathrm{Ph}$ & 2 & 96 & 88 & $51: 49$ \\
\hline \multirow[t]{2}{*}{2} & 2b: $\mathrm{CH}\left(\mathrm{CH}_{3}\right) \mathrm{Ph}$ & 2 & 96 & 93 & $10: 55$ \\
\hline & & & & & $25: 10^{d}$ \\
\hline 3 & 2c: $\mathrm{C}_{2} \mathrm{H}_{5}$ & 2 & 93 & 90 & $53: 47$ \\
\hline 4 & 2d: $n-\mathrm{C}_{10} \mathrm{H}_{21}$ & 2 & 99 & 97 & $50: 50$ \\
\hline 5 & 2e: $\left(\mathrm{CH}_{3}\right)_{3} \mathrm{C}$ & 2 & 47 & 48 & $30: 70$ \\
\hline 6 & 2f: $4-\mathrm{NO}_{2} \mathrm{C}_{6} \mathrm{H}_{4}$ & 2 & 95 & 91 & $40: 60$ \\
\hline 7 & 2g: $4-\mathrm{ClC}_{6} \mathrm{H}_{4}$ & 3 & 82 & 71 & $64: 36$ \\
\hline \multirow[t]{2}{*}{8} & 2h: $\mathrm{C}_{6} \mathrm{H}_{5}$ & 2 & 35 & 35 & $69: 31$ \\
\hline & & 24 & 34 & nd & \\
\hline
\end{tabular}

Table 1. Reaction of Different Aldehydes with Nitroethane in the Presence of Catalyst $1 \mathrm{a}^{a}$

${ }^{a}$ All reactions were carried out at $25{ }^{\circ} \mathrm{C}$ under solventless conditions. The molar ratio nitroethane/aldehyde and catalyst/aldehyde were of 1.2 and 0.01 , respectively. ${ }^{b}$ Isolated yield of nitroaldols after purification through silica gel. ${ }^{c}$ Determined by ${ }^{1} \mathrm{H} \mathrm{NMR}^{13}{ }^{d_{2} \mathbf{b}}$ generated 4 diastereoisomers.

determined by NMR, the isolated yield of such products after FFC purification on silica, and the diasteroselectivity of the reaction.

Results for catalyst 1a are summarized in Table 1.
Equilibrium conditions of all Henry additions were achieved rapidly in the chosen experiment time. Aliphatic aldehydes $\mathbf{2 a -}$ d were readily converted into the corresponding aldol derivatives $\mathbf{3 a}-\mathbf{d}$ which were isolated as highly pure $(>95 \%)$ products in excellent yields (88-97\%, entries 1-4). Pivalaldehyde (2e) however, gave product $3 \mathbf{e}$ in a $48 \%$ yield only: a result plausibly due to the steric hindrance of tert-butyl group.

The behavior of aromatic aldehydes was greatly affected by the nature of the aryl substituents. Compounds $2 \mathbf{f}-\mathbf{g}$, activated by EW groups $\left(p-\mathrm{Cl}\right.$ or $\left.p-\mathrm{NO}_{2}\right)$, offered results comparable to aliphatic substrates $\mathbf{2 a - d}$ (entries 5-6). This held true especially for $p$-nitrobenzaldehyde (2f), whose nitroaldol was isolated in $91 \%$ yield (entry 5). By contrast, the reaction of benzaldehyde reached a less favorable equilibrium position at which the conversion did not exceed $35 \%$, as confirmed also at prolonged reaction times (up to $24 \mathrm{~h}$, entry 6). Other investigations on the reversibility of the nitroaldol addition of benzaldehyde reported a similar behavior. ${ }^{10}$ Even more generally, recent studies confirmed that equilibrium constants of nucleophilic additions on aromatic aldehydes were altered by changing aryl substituents. ${ }^{14}$

Reactions of substrates $\mathbf{2 c}$ and $\mathbf{2 d}$ with nitroethane were carried out on a larger scale starting from $30 \mathrm{mmol}$ of aldehyde (1.74 and $4.68 \mathrm{~g}$ of $2 \mathrm{c}$ and $2 \mathrm{~d}$, respectively), methyl carbonate phosphonium salt (1a, $0.3 \mathrm{mmol}$ ), and nitroethane $(36 \mathrm{mmol})$. After $2 \mathrm{~h}$, both products $3 \mathrm{c}$ and $3 \mathrm{~d}$ were isolated in $92 \%$ (3.67 g) and $97 \%(6.73 \mathrm{~g})$ yields, respectively.

Finally, under the conditions of Table 1, hydrogen carbonate salt $\mathbf{1 b}$ did not show appreciable differences from methylcarbonate 1a. The reactions of aliphatic aldehydes catalyzed by $\mathbf{1 b}$, were as fast as with 1a, and no other practical advantages were observed during the isolation of the aldol products.

Henry Reaction of Different Aldehydes with Nitromethane. 3-Phenylpropanal and benzaldehyde (2a and $2 \mathbf{h}$ ) were chosen as models for aliphatic and aromatic aldehydes, respectively. They were set to react with nitromethane in the presence of salt 1a as the catalyst (conditions of Table 2: 1.5 mmol of aldehyde, 2a: $201 \mathrm{mg}, \mathbf{2 h}: 159 \mathrm{mg}$; the molar ratio nitromethane/aldehyde and catalyst/aldehyde were of 1.2 and 0.01 , respectively). Also in this case, the reaction was selective toward nitroaldols, and no other byproducts (nitroolefins, selfcondensation, or Cannizzaro products) were observed by NMR (Scheme 5).

At $25{ }^{\circ} \mathrm{C}$, after $2 \mathrm{~h}$, 3-phenylpropanal and benzaldehyde gave the corresponding nitroaldols in 96 and $77 \%$ isolated yields, respectively. In particular, benzaldehyde derivative $4 \mathrm{~h}$ from nitromethane was obtained in a better yield than the analogue

\begin{tabular}{|c|c|c|c|c|c|c|c|c|c|}
\hline \multirow[b]{2}{*}{ entry } & \multirow[b]{2}{*}{ ketone } & \multirow[b]{2}{*}{$1 \mathrm{a}: 5^{a}(\mathrm{~mol} / \mathrm{mol})$} & \multirow[b]{2}{*}{$\mathrm{MeNO}_{2}: 5^{b}(\mathrm{~mol} / \mathrm{mol})$} & \multirow[b]{2}{*}{$T\left({ }^{\circ} \mathrm{C}\right)$} & \multirow[b]{2}{*}{ conv (\%, by NMR) } & \multicolumn{2}{|c|}{$\begin{array}{c}\text { products (\%, by } \\
\text { NMR) }\end{array}$} & \multicolumn{2}{|c|}{ yield $^{c}(\%)$} \\
\hline & & & & & & 7 & 8 & 7 & 8 \\
\hline 1 & $5 a$ & 0.1 & 1.2 & 25 & 63 & 61 & 2 & 58 & \\
\hline 2 & $5 a$ & 0.2 & 5.0 & 50 & 74 & 22 & 52 & & \\
\hline 3 & $5 a$ & 0.5 & 5.0 & 50 & 88 & 8 & 80 & & 81 \\
\hline 4 & $5 b$ & 0.1 & 1.2 & 25 & 39 & 27 & 12 & 25 & \\
\hline 5 & $5 b$ & 0.2 & 5.0 & 50 & 74 & 3 & 71 & & \\
\hline 6 & $5 b$ & 0.5 & 5.0 & 50 & 93 & 1 & 92 & & 91 \\
\hline
\end{tabular}
product from nitroethane ( $3 \mathrm{~h}$ : $34 \%$, Table 2 ). The relative

Table 2. Henry Reaction of Cyclic Ketones ( $5 a$ and $5 b$ ) with Nitromethane Catalyzed by $1 a$

${ }^{a}$ All reactions were carried out under solventless conditions and for $20 \mathrm{~h}$. The molar ratio catalyst/ketone. ${ }^{b}$ The molar ratio nitromethane/ketone. ${ }^{c}$ Isolated yields of nitroaldols $\mathbf{7 a}$ and $\mathbf{7 b}$ or dinitromethylderivative $\mathbf{8 a}$ and $\mathbf{8 b}$, after purification through silica gel. 
Scheme 5

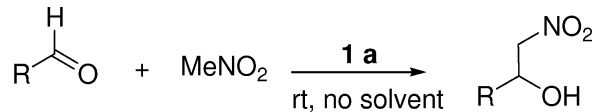

$$
\begin{aligned}
& \begin{array}{ll}
\text { 2a: } \mathrm{R}=\mathrm{CH}_{2} \mathrm{CH}_{2} \mathrm{Ph} & \mathbf{4 a :} 96 \% \\
\text { 2h: } \mathrm{R}=\mathrm{C}_{6} \mathrm{H}_{5} & \mathbf{4 h}: 77 \%
\end{array}
\end{aligned}
$$

stabilities of compounds $3 \mathrm{~h}$ and $\mathbf{4 h}$ plausibly accounted for such a result.

Henry Reaction of Different Ketones with Nitroalkanes. In the literature, several examples reported that Henry additions of ketones were quite less effective than those of aldehydes. ${ }^{15}$ Both electronic and steric effects were claimed to account for this difference, and in most cases, $\mathrm{C}_{5}-\mathrm{C}_{6}$ cyclic ketones were good model substrates to investigate such an aspect. These observations prompted us to explore the reactions of cyclohexanone and cyclopentanone (5a and $\mathbf{5 b}$, respectively) with nitroethane and nitromethane, respectively, in the presence of salt 1a as the catalyst.

Nitroethane. Experiments were carried out at $25{ }^{\circ} \mathrm{C}$ for 20 h. Nitroethane (0.45-1.88 g) and the ketone (5a: $490 \mathrm{mg}$; 5b: $420 \mathrm{mg}$ ) were mixed in a 1.2:5 molar ratio, while the salt 1a was used in $0.1-0.5$ molar equiv with respect to the ketone (1a: 246-1230 mg) (Scheme 6; for further details, see the

Scheme 6

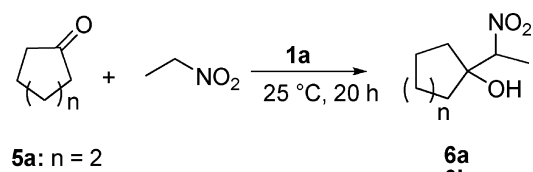

5a: $\mathrm{n}=2$

$6 a$

Experimental Section). ${ }^{1} \mathrm{H}$ NMR analysis showed that the Henry condensation proceeded selectively to the expected nitroaldol derivatives $(\mathbf{6 a}, \mathbf{b})$. However, under the conditions used for aldehydes (Table 1), conversions of both cyclohexanone and cyclopentanone were of only $23 \%$ and $10 \%$, respectively, even after a prolonged reaction time $(20 \mathrm{~h})$.

The increase of the catalyst loading ( $1 \mathrm{a} / 5$ from 0.1 to 0.5 ) favored the formation of nitroaldols $\mathbf{6 a}$ and $\mathbf{6 b}$ : the corresponding isolated yields were of $57 \%$ and $17 \%$. Larger amounts of both the salt 1a and nitroethane (up to 1 and 5 molar equiv, respectively) did not further improve the reaction outcome. ${ }^{16}$ For comparison, it should be noted that different procedures for the synthesis of 6 a claimed yields in the range of $22-82 \%{ }^{17}$ while the isolation (or yield) of nitroaldol $6 \mathbf{b}$ was never reported.

Nitromethane. Experiments were carried out at two different temperatures of 25 and $50{ }^{\circ} \mathrm{C}$ and for $20 \mathrm{~h}$. The Henry reactants were mixed in a 1.2:5 molar ratio (nitromethane: 366-1525 mg; $490 \mathrm{mg}$; 5b: $420 \mathrm{mg}$ ), while the catalyst 1a $(246-1230 \mathrm{mg})$ was used in $0.1-0.5$ molar equiv with respect to the ketone (for further details, see the Experimental Section). Under such conditions, ${ }^{1} \mathrm{H}$ NMR analysis showed the formation of nitroaldols $(7 \mathbf{a}, \mathbf{b})$ and dinitromethyl derivatives 8a,b. (Scheme 7).

Results are summarized in Table 2 .

Since the (methylene)nitronate was a powerful nucleophile, conversions of ketones $\mathbf{5 a}$ and $\mathbf{5 b}$ were generally higher than those observed with nitroethane (entries 1 and 4). However, the most significant effect was the dramatic change of the product distribution induced by the combined increases of both
Scheme 7

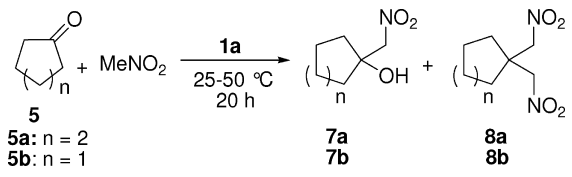

the catalyst and nitroalkane amounts, as well as by the temperature.

At $25{ }^{\circ} \mathrm{C}$, in the presence of $10 \mathrm{~mol} \%$ of $1 \mathrm{a}$, conversions were in the range of $39-63 \%$ and nitroaldols were the major products: the reaction of cyclohexanone proceeded with a good selectivity (up to 97\%) toward $7 \mathbf{a}$, while cyclopentanone yielded derivatives $7 \mathbf{b}$ and $\mathbf{8 b}$ in a 2:1 ratio, respectively (entries 1 and 4).

When the temperature was increased to $50{ }^{\circ} \mathrm{C}$ and additional amounts of both nitromethane and catalyst la were used (nitromethane/ketone and catalyst/ketone molar ratios of 5 and $0.2-0.5$, respectively), the reactions proceeded further and afforded the products of double addition of nitromethane 8a and $\mathbf{8 b}$ on an almost exclusive basis. Conversions of cyclohexanone and cyclopentanone increased up to $88 \%$ and $93 \%$, and the corresponding dinitromethyl derivatives $\mathbf{8 a}$ and $\mathbf{8 b}$ were isolated in excellent yields ( 81 and $91 \%$, respectively, entries 3 and 6). For comparison, in the representative work of Kisanga et al., ${ }^{17 c}$ the formation of products $8 \mathbf{a}$ and $\mathbf{8 b}$ from the reaction of ketones and nitromethane was observed only when a very strong neutral base (proazaphosphatrane, $30 \% \mathrm{~mol}$ ) was used. However, yields did not exceed $21 \%$ even in the presence of overstoichiometric amounts of $\mathrm{MgSO}_{4}$ as a carbonyl group activator and a rigorously inert atmosphere.

Overall, the results of Scheme 6 and Table 2 confirmed the efficiency of CILs as base catalysts also for the Henry addition to ketones. In the case of nitromethane, although the reaction hardly stopped to nitroaldol derivatives, the procedure unlocked the potential of CILs to access dinitromethyl derivatives 8 hitherto difficult to prepare.

Mechanism and Role of the Catalyst. The reaction of cyclic ketones with nitromethane yielding both nitroaldols 7 and dinitromethyl derivatives $\mathbf{8}$ was chosen as a model for a mechanistic hypothesis (Scheme 8).

An initial acid-base reaction between the salt 1 a and nitromethane generated the active nucleophile, i.e. the nitronate onium salt $\left(\mathrm{Q}^{+} \mathrm{CH}_{2} \mathrm{NO}_{2}^{-}\right)$, along with the rather unstable methyl carbonic acid $\left(\mathrm{MeOCO}_{2} \mathrm{H}\right)^{18}$ that readily decomposed to $\mathrm{CO}_{2}$ and methanol (top cycle). Then, a nucleophilic addition of $\mathrm{Q}^{+} \mathrm{CH}_{2} \mathrm{NO}_{2}^{-}$to the ketone carbonyl followed by a second acid/base reaction with methanol produced the nitroaldol 7 and a methoxide onium salt $\left(\mathrm{Q}^{+} \mathrm{MeO}^{-}\right)$. Although the existence of methoxide ionic liquids was only recently reported, ${ }^{19}$ the reversible trapping of $\mathrm{CO}_{2}$ by simple alkoxide anions was a well-known process. $^{20}$ (Scheme 9).

In our case, this explained the restoration of catalyst 1a (Scheme 8, top cycle, left).

The reaction could stop at this stage or, if an excess of nitromethane and a higher temperature $\left(50^{\circ} \mathrm{C}\right)$ were used, it could proceed further via the nucleophilic displacement of the nitronate salt $\left(\mathrm{Q}^{+} \mathrm{CH}_{2} \mathrm{NO}_{2}^{-}\right)$on nitroaldol 7. Although $\mathrm{OH}^{-}$is not a good leaving group, the great affinity between phosphorus (of $\mathrm{Q}^{+}$cation) and oxygen atoms may assist the simultaneous formation of hydroxide salt $\left(\mathrm{Q}^{+} \mathrm{OH}^{-}\right)$and dinitromethyl product 8 (bottom). ${ }^{21}$ In analogy to Scheme 8 , the $\mathrm{CO}_{2}$ 


\section{Scheme 8}

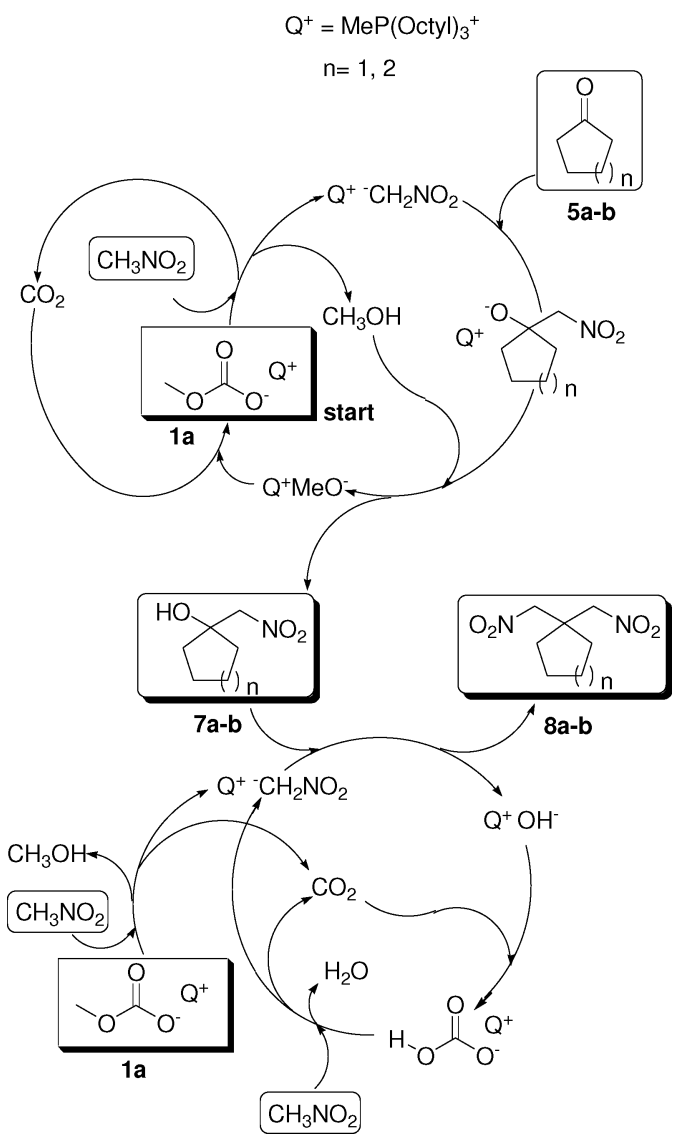

Scheme 9

$\mathrm{MeO}^{-}+\mathrm{CO}_{2} \rightleftharpoons \mathrm{MeOCO}_{2}^{-}$

uptake by hydroxide produced $\mathrm{Q}^{+} \mathrm{HOCO}_{2}^{-}$which became the actual catalyst. ${ }^{22}$

The easy elimination of water from nitroaldols 7 might also be considered (Scheme 1): however, under the investigated conditions, this pathway was ruled out since not even traces of the expected products (nitroolefins) were observed. As for aldehydes, products of self-condensation of ketones were not detected.

Overall, the double addition of nitromethane to cyclic ketones was a genuine catalytic process, but the initial methyl carbonate catalyst 1a was plausibly transformed in the hydrogen carbonate analogue $\mathbf{1 b}$. This was corroborated by the fact that under the conditions of Table 2, also compound $\mathbf{1 b}$ was able to catalyze the formation of both products $8 \mathbf{a}$ and $8 \mathbf{b}$.

\section{CONCLUSIONS}

With a view to develop new superbase organocatalysts by using ILs properties, trioctyl methyl phosphonium methylcarbonate and bicarbonate salts (CILs 1a and $\mathbf{1 b}$ ) offers a promising and unexplored starting tool.

In the Henry reaction of both aldehydes and ketones, compounds $\mathbf{1 a}$ and $\mathbf{1 b}$ act as powerful task specific (basic) catalysts with performances comparable to those of sterically hindered (non-nucleophilic) strong bases such as DBU. Aldehydes allow the selective formation of the corresponding nitroaldols. For ketones, reaction conditions can be tuned to produce dinitromethyl compounds in excellent yields (80$90 \%)$. To our knowledge, the procedure here described offers some of the best ever reported results for the synthesis of such dinitromethyl ketone derivatives.

In both cases, a modest excess of nitroalkanes was used with no additional solvent.

The reaction mechanism plausibly involves the transformation of the initial catalytic species $\left[\mathrm{MeP}(\text { Octyl })_{3}{ }^{+}\right.$ $\left.\mathrm{ROCO}_{2}^{-} ; \mathrm{R}=\mathrm{Me}, \mathrm{H}\right]$ through reversible loss and uptake of $\mathrm{CO}_{2}$.

\section{EXPERIMENTAL SECTION}

General Methods. All reagents used were ACS grade and were used as received, except for liquid aldehydes that were distilled prior to their use.

Phenyltetramethylguanidine (PhTMG) was prepared from 1,1,3,3tetramethylurea and aniline using a reported procedure. ${ }^{23}$ Starting from $1.16 \mathrm{~g}$ of 1,1,3,3-tetramethylguanidine (10.0 mmol), $1.63 \mathrm{~g}$ of crude product was obtained. The product was purified by distillation $\left(85-100{ }^{\circ} \mathrm{C} ; 0.06 \mathrm{~atm}\right)$ to yield $1.35 \mathrm{~g}$ of pure PhTMG $(71 \%)$.

Methylcarbonate and bicarbonate phosphonium salts (CILs, 1a and 1b) were obtained according to a methodology previously reported by our group. ${ }^{24}$ Starting from $20.8 \mathrm{~g}$ of trioctylphosphine $(56.1 \mathrm{mmol})$, $30 \mathrm{~mL}$ of DMC, $30 \mathrm{~mL}$ of $\mathrm{MeOH}$, and $27.5 \mathrm{~g}$ of trioctylmethylphosphonium methylcarbonate $(55.8 \mathrm{mmol}$; 99\%) was obtained 1a. Product 1a $(3.00 \mathrm{~g} ; 6.09 \mathrm{mmol})$ was reacted with water $(1.00 \mathrm{~g} ; 55.6$ mmol) yielding $2.72 \mathrm{~g}(6.09 \mathrm{mmol} ; 100 \%)$ of $\mathbf{1 b}$.

${ }^{1} \mathrm{H}$ NMR and ${ }^{13} \mathrm{C}$ NMR spectra were collected in $\mathrm{CDCl}_{3}$ solution at $25^{\circ} \mathrm{C}$ at 400 and $100 \mathrm{MHz}$, respectively. Chemical shifts $(\delta)$ are reported in parts per million (ppm) downfield from TMS.

General Procedures. Addition of Nitroethane to 3-Phenylpropionaldehyde Catalyzed by Different Base Catalysts (Figure 1). An NMR tube was charged with PPA (67 mg; $0.5 \mathrm{mmol})$ in $\mathrm{CDCl}_{3}(1$ $\mathrm{mL}$ ) and set to react with a preformed solution of the selected base catalyst (0.025 mmol; triethylamine, $2.5 \mathrm{mg}$; DBU, $3.8 \mathrm{mg}$; DMAP, 3.1 mg; PhTMG, 4.8 mg; 1a, 11.5 mg; 1 b, $11.2 \mathrm{mg}$; 0.05 molar equiv with respect to $\mathrm{PPA})$ in nitroethane $(188 \mathrm{mg} ; 2.5 \mathrm{mmol}$; molar ratio nitroethane/PPA = 5). Once the tube was inserted in the NMR spectrometer, it was thermostated at $25{ }^{\circ} \mathrm{C}$. Then, spectra of the reacting mixture were recorded at time intervals. Experiments were carried out for $190 \mathrm{~min} .{ }^{1} \mathrm{H}$ NMR analyses of the reaction mixture showed that PPA produced the corresponding aldol derivative (3a) with no other side products.

Reaction of Different Aldehydes with Nitroethane in the Presence of CILs as Catalysts (Table 1). A 7-mL glass reactor shaped as a test tube was charged with the aldehyde $(1.5 \mathrm{mmol} ; 2 \mathrm{a}: 201 \mathrm{mg}$; 2b: $201 \mathrm{mg}$; 2c: $87 \mathrm{mg}$; 2d: $243 \mathrm{mg}$; 2e: 226 mg; 2f: $210 \mathrm{mg}$; 2g: 159 $\mathrm{mg}$ ) and a $0.116 \mathrm{M}$ solution of methylcarbonate phosphonium salt $\left(0.13 \mathrm{~mL}\right.$; 1a: $\left.7.4 \mathrm{mg} ; 1.5 \times 10^{-2} \mathrm{mmol}\right)$ in nitroethane. Under these conditions, the molar ratio nitroethane/ $\mathbf{2}$ and catalyst/2 were 1.2 and 0.01 , respectively.

The reactor was kept at room temperature $\left(25^{\circ} \mathrm{C}\right)$, and the mixture was kept under magnetic stirring throughout the reaction. After the desired time, usually $2 \mathrm{~h}$ (see Table 1 for details), the reaction mixture was quenched by adding a $1 \% \mathrm{HCl}$ aqueous solution $(1.0 \mathrm{~mL})$. A sample of the organic phase was then analyzed by ${ }^{1} \mathrm{H}$ NMR: the amount of nitroaldol products (3) were reported in Table 1 . Diethylether $(2 \mathrm{~mL})$ was added to the reaction mixture, and the extracted organic phase was filtrated on silica gel (2 g, eluant diethylether, $25 \mathrm{~mL}$ ) to remove the catalyst 1a. Finally, the resulting solution was rotary evaporated $\left(40{ }^{\circ} \mathrm{C}, 150 \mathrm{mbar}\right)$. The products 4 nitro-1-phenylpentan-3-ol (3a: $276 \mathrm{mg}$, yield $=88 \%$ ), 2-nitro-4phenylpentan-3-ol (3b: $291 \mathrm{mg}$, yield = 93\%), 2-nitropentan-3-ol (3c: $180 \mathrm{mg}$, yield $=90 \%)$, 2-nitrododecan-3-ol (3d: $336 \mathrm{mg}$, yield $=97 \%$ ), 2-nitro-1-(4-nitrophenyl)propan-1-ol (3e: $308 \mathrm{mg}$, yield = 91\%), 1-(4chlorophenyl)-2-nitropropan-1-ol (3f: $229 \mathrm{mg}$, yield $=71 \%$ ), and 2nitro-1-phenylpropan-1-ol $(3 \mathrm{~g}$ : $95 \mathrm{mg}$, yield $=35 \%)$ were obtained as a mixture of diastereoisomers and characterized by ${ }^{1} \mathrm{H}$ and ${ }^{13} \mathrm{C}$ NMR 
The above-described procedure was adapted for the following experiments [(i) and (ii)]: (i) Reactions Using Bicarbonate Phosphonium Salt (1b) as the Catalyst. With all the other conditions unaltered, catalyst $\mathbf{1 b}\left(6.7 \mathrm{mg} ; 1.5 \times 10^{-2} \mathrm{mmol}\right)$ was used in place of 1a. The results, not reported here, did not showed appreciable differences between the two catalytic systems. (ii) Reactions on Larger Scale Carried out Using Substrates $2 c$ and $2 d$. A 25-mL glass flask was charged with the aldehyde ( $30 \mathrm{mmol}$; $2 \mathrm{c}: 1.74 \mathrm{~g} ; 2 \mathrm{~d}: 4.68 \mathrm{~g})$, methyl carbonate phosphonium salt (1a, $0.3 \mathrm{mmol}, 148 \mathrm{mg}$ ) and nitroethane $(36 \mathrm{mmol} ; 2.7 \mathrm{~g})$. Under these conditions, the molar ratio nitroethane: 2 and catalyst: 2 were 1.2 and 0.01 , respectively. The reactions were carried out at $25{ }^{\circ} \mathrm{C}$ for $2 \mathrm{~h}$, then a $1 \% \mathrm{HCl}$ aqueous solution was added $(10 \mathrm{~mL})$. Once the aqueous phase was removed, the nitroaldol products were purified through a filtration on silica gel ( $5 \mathrm{~g}$ of silica gel, $200 \mathrm{~mL}$ of diethylether). Products were obtained with high purity (95\%): $3 \mathrm{c}(3.67 \mathrm{~g})$ and $3 \mathrm{~d}(6.72 \mathrm{~g})$ were isolated in 92 and $97 \%$ yields, respectively.

Addition of Nitroethane to Cyclic Ketones in the Presence of CILs as Catalyst. A 7-mL glass reactor shaped as a test tube was charged with the ketone (5: $5.0 \mathrm{mmol}$; 5a: $490 \mathrm{mg}$ 5b: $420 \mathrm{mg}$ ), phosphonium salt (1a: 246, 492, $1230 \mathrm{mg}$; 0.5, 1, $2.5 \mathrm{mmol}$ ), and nitroethane (450 mg and $1875 \mathrm{mg} ; 6.0$ and $25.0 \mathrm{mmol}$ ). Molar ratios nitroethane/ketone and $1 \mathrm{a} /$ ketones were in the range of 1.2-5.0 and $0.1-0.5$, respectively. The mixture was kept under magnetic stirring at room temperature for $20 \mathrm{~h}$. Then, the reaction was quenched by adding a $5 \% \mathrm{HCl}$ aqueous solution $(3.0 \mathrm{~mL})$. The resulting mixture was extracted with diethylether $(2.0 \mathrm{~mL})$ from which products $6 \mathbf{a}$ and $\mathbf{6 b}$ were isolated. These compounds were purified by column chromatography (eluant: ethylacetate/petroleum ether mixture, 30/ $70 \mathrm{v} / \mathrm{v})$ yielding pure 1-(1-nitroethyl)cyclohexanol (6a, $248 \mathrm{mg}$, yield $=57 \%)$ and 1-(1-nitroethyl)cyclopentanol $(6 \mathrm{~b}, 69 \mathrm{mg}$, yield $=17 \%)$.

Addition of Nitromethane to Cyclic Ketones in the Presence of CILs as Catalyst. Reactions of Table 2 were carried out according to the following procedure. A 7-mL glass reactor shaped as a test tube, was charged with the ketone (5: $5.0 \mathrm{mmol}$; 5a: $490 \mathrm{mg}$; 5b: $420 \mathrm{mg}$ ), phosphonium salt (1a: 246, 492, $1230 \mathrm{mg} ; 0.5,1,2.5 \mathrm{mmol}$ ) and nitromethane (366 mg and $1525 \mathrm{mg}$; 6.0, $25.0 \mathrm{mmol}$ ). Molar ratios nitroethane/ketone and $1 \mathrm{a} /$ ketones were in the range of 1.2-5.0 and $0.1-1.0$, respectively.

The reactor was heated at the desired temperature $\left(25-50{ }^{\circ} \mathrm{C}\right.$, see Table 2 for details), and the mixture was kept under magnetic stirring throughout the reaction. After $20 \mathrm{~h}$, the reaction was quenched by adding a $5 \% \mathrm{HCl}$ aqueous solution $(3.0 \mathrm{~mL})$.

At the end of reactions of entries 1, 3, 4, and 6 of Table 2, diethyl ether $(3 \mathrm{~mL})$ was added to the reaction mixtures and the aqueous phase was separated. Products were purified by column chromatography (eluant: ethyl acetate/petroleum ether mixture, 30/70 v/v) yielding 1-(nitromethyl)cyclohexanol $(7 \mathrm{a}, 461 \mathrm{mg}$, yield $=58 \%), 1$ (nitromethyl)cyclopentanol (7b, $200 \mathrm{mg}$, yield $=25 \%$ ), 1,1-bis(nitromethyl)cyclohexane $(8 \mathrm{a}, 410 \mathrm{mg}$, yield $=81 \%), 1,1$-bis(nitromethyl)cyclopentane $(\mathbf{8 b}, 426 \mathrm{mg}$, yield $=91 \%)$. The structures of all products were confirmed by ${ }^{1} \mathrm{H}$ and ${ }^{13} \mathrm{C}$ NMR.

\section{ASSOCIATED CONTENT}

\section{(5 Supporting Information}

Characterization data and NMR spectra of compound $\mathbf{6 b}$. This material is available free of charge via the Internet at http:// pubs.acs.org.

\section{AUTHOR INFORMATION}

\section{Corresponding Author}

*E-mail: selva@unive.it.

\section{Notes}

The authors declare no competing financial interest.

\section{ACKNOWLEDGMENTS}

MIUR (Italian Ministry of University and Research, Research Grant PRIN 2008) is gratefully acknowledged for financial support.

\section{REFERENCES}

(1) Chakraborti, A. K.; Sudipta, R. R. J. Am. Chem. Soc. 2009, 131, 6902-6903.

(2) (a) Parvulescu, V. I.; Hardacre, C. Chem. Rev. 2007, 107, 2615266. (b) Zhang, Z. C. Adv. Catal. 2006, 49, 153-237. (c) Welton, T. Coord. Chem. Rev. 2004, 248, 2459-2477.

(3) Lee, J. W.; Shin, J. Y.; Chun, Y. S.; Jang, H. B.; Song, C. E.; Lee, S.-G. Acc. Chem. Res. 2010, 43, 985-994.

(4) (a) Rosini, G. In Comprehensive Organic Synthesis; Trost, B. M., Ed.; Pergamon: Oxford, 1999; Vol. 1. (b) Ono, N. In The Nitro Group in Organic Synthesis; Feuer, H., Ed.; Wiley-VCH: New York, 2001. (c) Ballini, R; Bosica, G. J. Org. Chem. 1997, 62, 425. Luzzio, F. A. Tetrahedron 2001, 57, 915-945.

(5) (a) Palomo, C.; Oiarbide, M.; Laso, A. Angew. Chem., Int. Ed. 2005, 44, 3881-3884. (b) Nugent, B. M.; Yoder, R. A.; Johnston, J. N. J. Am. Chem. Soc. 2004, 126, 3418-3419. (c) Kumar, A.; Pawar, S. S. J. Mol. Catal. A: Chem. 2005, 235, 244-248. (d) Jiang, T.; Gao, H.; Han, B.; Zhao, G.; Chang, Y.; Wu, W.; Gao, L.; Yang, G. Tetrahedron Lett. 2004, 45, 2699-270. (e) Burguete, M. I.; Erythropel, H.; GarciaVerdugo, E.; Luis, S. V.; Sans, V. Green Chem. 2008, 10, 401-407. (f) McNulty, J.; Larichev, D. V.; Capretta, A.; Robertson, A. J. Lett. Org. Chem. 2004, 1, 137-139.

(6) Italian Ministry Research Grant (PRIN 2008) 200895XNPL_004

(7) Fabris, M.; Lucchini, V.; Noè, M.; Perosa, A.; Selva, M. Chem.Eur. J. 2009, 15, 12273-12282.

(8) Selva, M.; Tundo, P. Acc. Chem. Res. 2002, 35 (9), 706-716.

(9) Cunningham, I. D.; Woolfall, M. J. Org. Chem. 2005, 70, 92489256.

(10) Aliphatic aldehydeswere convenient substrates for preliminary tests of Henry reactions. Ono, F.; Soejima, H.; Tanaka, J.; Kanemasa, S. Eng. Sci. Rep. Kyushu Univ. 2008, 1, 25-28.

(11) Kaljurand, I.; Kutt, A.; Soovali, L.; Rodima, T.; Maemets, V.; Leito, I.; Koppel, I. A. J. Org. Chem. 2005, 70, 1019-1028.

(12) Under a $0.01 \mathrm{CIL} /$ substrate ratio, the aldol formation rapidly decreased. A plausible reason was the contamination of the reacting aldehyde with trace levels of the corresponding (carboxylic) acid, able to neutralize the basic salt. For this reason, freshly distilled aldehydes were always used.

(13) The syn/anti ratio was determined according to NMR analyses reported in the literature, in which usually, $J_{a n t i}<J_{s y n}$ : (a) Seebach, D.; Beck, A. K.; Mukhopadhyay, T.; Thomas, E. Helv. Chim. Acta 1982, 65, 1101-1133. (b) Ballini, R.; Bosica, G.; Marcantoni, E.; Vita, P. J. Org. Chem. 2000, 65, 5854-5857.

(14) Crugeiras, J.; Rios, A.; Riveiros, E.; Richard, J. P. J. Am. Chem. Soc. 2009, 131, 15815-15824.

(15) (a) Simoni, D.; Invidiata, F. P.; Manfrenidi, S.; Ferroni, R.; Lampronti, I.; Roberti, M.; Pollini, G. P. Tetrahedron Lett. 1997, 38, 2749. (b) Gan, C.; Chen, X.; Lai, G.; Wang, Z. Synlett 2006, 3, 387390.

(16) Additional experiments showed that even the increase of the temperature from 25 to $50{ }^{\circ} \mathrm{C}$, was not of help since the reaction selectivity dropped due to the onset of side processes. The structures of the corresponding products were not assigned.

(17) (a) Fraser, H. B.; Kon, G. A. R. J. Chem. Soc. 1934, 604-610. (b) Buehler, C. A.; Pruett, R. L. J. Am. Chem.. Soc. 1951, 73, 55045506. (c) Kisanga, P. B.; Verkade, J. G. J. Org. Chem. 1999, 64, 42984303. (d) Simoni, D.; Rondanin, R.; Morini, M.; Baruchello, R.; Invidiata, F. P. Tetrahedron Lett. 2000, 41, 1607-1610.

(18) Gattow, G.; Behrendt, W. Angew. Chem., Int. Ed. Engl. 1972, 11, 534-535.

(19) Eta, V.; Makiarvela, P.; Salminen, E.; Salmi, T.; Murzin, D. Y.; Mikkola, J.-P. Catal. Lett. 2011, 141, 1254-1261. 
(20) (a) Faurholt, C. Z. Physik. Chem. 1927, 126, 86. (b) Mandal, S. K.; Ho, D. M.; Orchin, M. Organometallics 1993, 12, 1714-1719. (c) Heston, B. O.; Dermeer, O. C.; Woodside, J. A. Proc. Oklahoma Acad. Sci. 1942, 67-68.

(21) (a) Kirbyand, A. J.; Warren, S. G. In The Organic Chemistry of Phosphorus; Elsevier: Amsterdam, 1967. (b) Chen, J.; Chen, Y.; Niu, Y.-L.; Fu, H.; Zhao, Y.-F. J. Mass Spectrom. 2002, 37, 934-939. (c) Schmidbaur, H.; Buchner, W.; Kohler, F. H. J. Am. Chem. Soc. 1974, 96, 6208-6210.

(22) Pinsent, B. R. W.; Pearson, L.; Roughton, F. J. W. J. Chem. Soc. 1956, 1512-1520.

(23) Cunningham, I. D.; Woolfall, M. J. Org. Chem. 2005, 70, 92489256.

(24) Fabris, M.; Lucchini, V.; Noè, M.; Perosa, A.; Selva, M. Chem.Eur. J. 2009, 15, 12273-12282. 